\title{
ChemComm
}

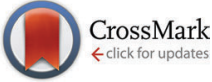

Cite this: Chem. Commun., 2016, 52,5932

Received 26th February 2016 Accepted 24th March 2016

DOI: $10.1039 / \mathrm{c} 6 \mathrm{cc} 01748 \mathrm{~g}$

www.rsc.org/chemcomm

\section{Conformational changes and chiroptical switching of enantiopure bis-helicenic terpyridine upon $\mathrm{Zn}^{2+}$ binding $\dagger$}

\author{
Helena Isla, ${ }^{a}$ Monika Srebro-Hooper, ${ }^{* b}$ Marion Jean, ${ }^{c}$ Nicolas Vanthuyne, \\ Thierry Roisnel, ${ }^{a}$ Jamie L. Lunkley, ${ }^{d}$ Gilles Muller, ${ }^{d}$ J. A. Gareth Williams, \\ Jochen Autschbach ${ }^{f}$ and Jeanne Crassous ${ }^{* a}$
}

The molecular conformation of a bis-helicenic terpyridine system is strongly modified upon binding to $\mathrm{Zn}(\mathrm{II})$ ion, a process that is accompanied by large changes in the optical and chiroptical properties. This system affords a new type of helicene-based chiroptical switching.

The contribution of chiroptical molecular switches ${ }^{1}$ to the field of functional devices is stimulated by many potential applications such as molecular information processing, data storage, or probes for the detection of chirality. ${ }^{2}$ Interconversion between two or more stable chiral forms can result from responses of chiral molecules to external stimuli such as heat, light, pressure, solvent, $\mathrm{pH}$, change in redox potential or presence of chemicals. The response at the molecular level can be transduced to a read-out process through the effect on chiroptical activity; e.g., optical rotation, electronic circular dichroism (ECD), and circularly polarized luminescence (CPL). Efficient, practicable switching between two (or more) molecular states, is based on stability, non-destructive read-out, fast response times, reproducibility and fatigue resistance. An important requirement is a large response difference between the states to ensure unambiguous read-out.

In the last decade, helicenes have appeared as attractive candidates for molecular materials and chiroptical switches due to their helical $\pi$-conjugated structure which gives rise to strong chiroptical properties such as huge optical rotation values, intense ECD spectra and significant CPL activity. ${ }^{3}$ Examples of

\footnotetext{
${ }^{a}$ Institut des Sciences Chimiques de Rennes, UMR 6226, Campus de Beaulieu, CNRS-Université de Rennes 1, 35042 Rennes Cedex, France.

E-mail: jeanne.crassous@univ-rennes1.fr

${ }^{b}$ Department of Theoretical Chemistry, Faculty of Chemistry, Jagiellonian University, 30-060 Krakow, Poland. E-mail: srebro@chemia.uj.edu.pl ${ }^{c}$ Aix Marseille Université, Centrale Marseille, CNRS, iSm2 UMR 7313, 13397, Marseille, France

${ }^{d}$ Department of Chemistry, San José State University, San José, CA 95192-0101, USA

${ }^{e}$ Department of Chemistry, University of Durham, Durham, DH1 3LE, UK

${ }^{f}$ Department of Chemistry, University at Buffalo, State University of New York, Buffalo, NY 14260, USA

$\dagger$ Electronic supplementary information (ESI) available: Synthetic, spectroscopic and computational details. CCDC 1448892-1448894. For ESI and crystallographic data in CIF or other electronic format see DOI: 10.1039/c6cc01748g
}

helicene-based chiroptical switches have been recently reviewed. ${ }^{4}$ However, the creation of structural diversity is still necessary to develop new kinds of functions in helicene-based chiral systems and to create innovative molecular devices. In this regard, several transition-metal complexes formed from helical $\pi$-conjugated ligands have recently been shown to display unprecedented chiroptical and electronic properties that are switchable by redox or acid/base stimuli. ${ }^{5}$ While in those examples the helical topology and integrity of the chemical backbone was maintained upon switching, constructing a scaffold in which movements can take place through geometrical and conformational changes is particularly appealing. Such conformational changes in chiral systems may lead to molecular motors with effective unidirectional motion. ${ }^{2,6}$

In this communication, we describe the synthesis of the first bishelicenic terpyridine ligand (meso-, $(M, M)$ - and $(P, P)-\mathbf{1}$ in Scheme 1) acting as a chiroptical switch upon reversible coordinationdecoordination of zinc(II). The profound conformational changes induced lead to a multi-output read-out system, showing responses in ECD, fluorescence and CPL-activity. The (chir)optical changes accompanying the interconversion between the ligand and zinccomplexed states have been analyzed via first-principles calculations.

The synthesis of ligand $\mathbf{1}$ was accomplished as described in Scheme 1. First, a Wittig reaction between terpyridine bisaldehyde $2^{7 a}$ and (benzo[c]phenanthren-3-ylmethyl)triphenylphosphonium bromide $3^{7 b}$ yielded bis-olefin 4 as a mixture of three isomers ( $E, E$ - major compound, $Z, Z$, and $E, Z)$. Subsequent photo-irradiation ( $700 \mathrm{~W} \mathrm{Hg}$ lamp) in a toluene/THF mixture at room temperature (r.t.) in the presence of catalytic iodine, furnished bis-helicene-terpyridine $\mathbf{1}$ as a statistical mixture of $(M, P)-\mathbf{1}($ meso-1) and racemic $(P, P)$ - and $(M, M)$-1. The structure of meso-1 was confirmed by NMR spectroscopy and by X-ray diffraction studies. The ${ }^{1} \mathrm{H}$ NMR spectrum is in agreement with its $C_{\mathrm{s}}$ symmetry and displays the typical signature of [6] helicene derivatives such as for example degenerate triplets at 6.8 and $7.3 \mathrm{ppm}$ corresponding to $\mathrm{H}^{15}$ and $\mathrm{H}^{14}$, respectively (see ESI $\dagger$ ). Thanks to its low solubility, meso-1 easily crystallized in the centrosymmetric $C \mathrm{~cm} 2_{1}$ space group, with the nitrogen atoms of adjacent pyridyl rings disposed trans to one another, as is 


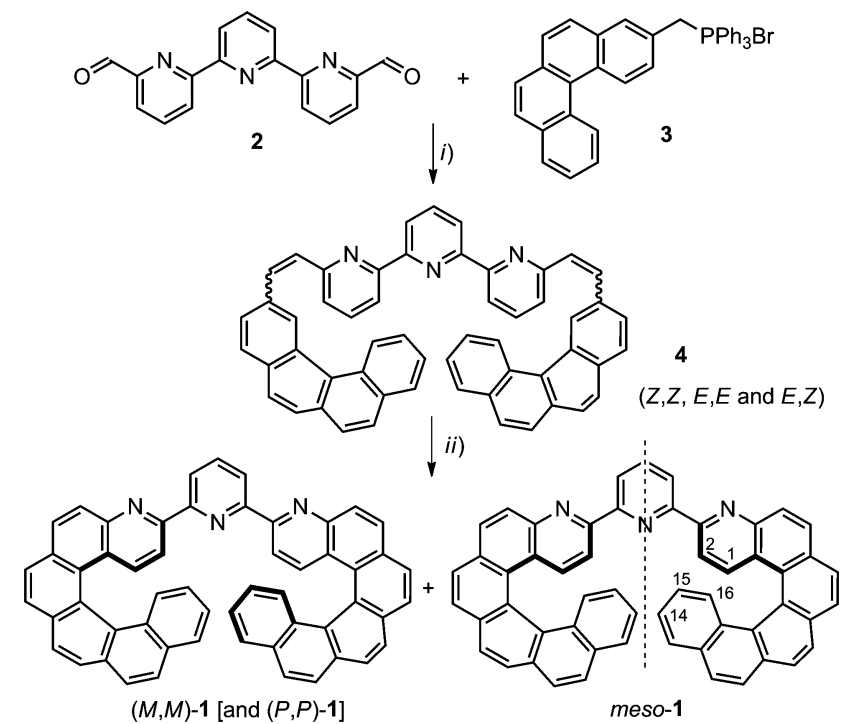

Scheme 1 Synthesis of bis-helicenic terpyridine 1. (i) $n$-BuLi, THF, r.t., 5 h, $82 \%$; (ii) $h \nu$, cat. $I_{2}$, toluene/THF, r.t., 7 h, $45 \%$.

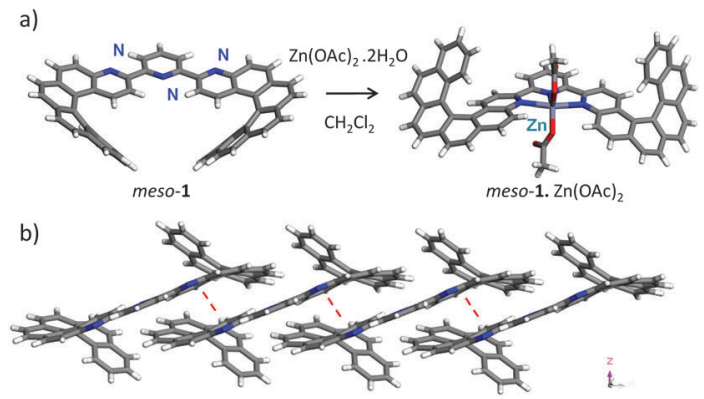

Scheme 2 (a) Coordination of achiral ligand meso-1 to $\mathrm{Zn}^{2+}$, generating meso-1. $\mathrm{Zn}(\mathrm{OAc})_{2}$ and their respective $\mathrm{X}$-ray crystal structures. (b) $\mathrm{X}$-ray structure and supramolecular arrangement of $(P, P)-\mathbf{1}$ along the $x$ axis in the solid state.

usual in 2,2' $: 6^{\prime}, 2^{\prime \prime}$-terpyridines (Scheme 2a). ${ }^{8}$ The structure also confirms (i) the $C_{\mathrm{s}}$ symmetry of the achiral meso compound; (ii) the high degree of planarity of the terpy moiety (dihedral angles between the different pyridine rings $<6.5^{\circ}$ ); and (iii) values for the helical angle (angle between the terminal rings) of the azahelicene moieties that are typical of such units $\left(51.83^{\circ}\right) .^{3}$

Pure samples of $(M, M)$ - and $(P, P)$-1 were successfully obtained from the crude stereoisomeric mixture by using HPLC over a chiral stationary phase and were then fully characterized (see ESI $\dagger$ ). They display different ${ }^{1} \mathrm{H}$ NMR spectra from the meso-1 compound in agreement with different orientation of helicenic moieties (for instance $\mathrm{H}^{15}$ and $\mathrm{H}^{14}$ resonate at 6.7 and 7.1, ppm, respectively). The X-ray structure of $(P, P)-\mathbf{1}\left(P 2_{1} 22_{1}\right.$ space group; Scheme $2 \mathrm{~b}$ ) shows (i) $C_{2}$ symmetry as opposed to the $C_{\mathrm{s}}$ symmetry of the meso isomer; (ii) again a high degree of planarity within the terpy moiety (dihedral angles between the pyridine rings $<8.3^{\circ}$ ) and a trans disposition of $\mathrm{N}$ atoms in adjacent rings; and (iii) typical values for the helical angle of the azahelicene moieties $\left(60.84^{\circ}\right) .^{3}$ Furthermore, compound $(P, P)-\mathbf{1}$ displays intermolecular organization along the $x$ axis thanks to the presence of $\pi$-stacking interactions (centroid-centroid distances $3.67 \AA$ A; Scheme 2b).
Compounds meso-1 and $\left(P^{*}, P^{*}\right)-\mathbf{1} \ddagger$ display photophysical properties with similar characteristics to one another (see ESI $\dagger$ ). For example, the UV-visible spectra of these two compounds show a very strong absorption band centred at about $320 \mathrm{~nm}$ $\left(\varepsilon \sim 6 \times 10^{4} \mathrm{M}^{-1} \mathrm{~cm}^{-1}\right)$ and a set of bands extending into the visible region, of gradually diminishing intensity, of which the longest wavelength appears at $416 \mathrm{~nm}\left(\varepsilon=5-8 \times 10^{3} \mathrm{M}^{-1} \mathrm{~cm}^{-1}\right)$. $\left(P^{*}, P^{*}\right)-1 \ddagger$ displays intense blue fluorescence in $\mathrm{CH}_{2} \mathrm{Cl}_{2}$ at r.t. ( $\left.\lambda_{\max }=421 \mathrm{~nm}, \phi=8.4 \%, \tau=5.7 \mathrm{~ns}\right)$. Its structured emission spectrum is characterised by a vibronic progression of $\sim 1350 \mathrm{~cm}^{-1}$, with the maximum intensity being in the $0-0$ band, indicative of a rigid aromatic fluorophore. In a frozen glass at $77 \mathrm{~K}$, the fluorescence is accompanied by long-lived green phosphorescence $\left(\lambda_{\max }=532 \mathrm{~nm}, \tau=1.4 \mathrm{~s}\right.$ ), with similar vibrational structure. Similar spectra were recorded for meso-1. The emission properties are in line with previously described nitrogen-containing [6] helicene derivatives. ${ }^{5 d}$

The chiroptical properties of $(M, M)$ - and $(P, P)-\mathbf{1}$ were then studied. High specific and molar optical rotation values were obtained $\left((P, P)-1:[\alpha]_{\mathrm{D}}^{23}=+2150\left[\% /\left(\mathrm{dm} \mathrm{g} / \mathrm{cm}^{-3}\right)\right],[\phi]_{\mathrm{D}}^{23}=+15790\left[{ }^{\circ} \mathrm{cm}^{2} \mathrm{dmol}^{-1}\right]\right.$ $\left.\left( \pm 5 \%, \mathrm{CH}_{2} \mathrm{Cl}_{2}, 2.2 \times 10^{-4} \mathrm{M}\right)\right)$. The molar rotation is twice as high as for 4-aza[6] helicene $\left([\alpha]_{\mathrm{D}}^{23}=+2290,[\phi]_{\mathrm{D}}^{23}=+7735\left( \pm 5 \%, \mathrm{CH}_{2} \mathrm{Cl}_{2}\right.\right.$, $C 1.7 \mathrm{~g} / 100 \mathrm{~mL}))^{9}$ in agreement with the presence of two azahelicene moieties. Similarly, very strong mirror-image ECD spectra were recorded for $(M, M)$ - and $(P, P)-\mathbf{1}$ enantiomers (Fig. 1), with a strong negative band around $264 \mathrm{~nm}\left(\Delta \varepsilon=-280 \mathrm{M}^{-1} \mathrm{~cm}^{-1}\right)$ and strong positive one at $341\left(+388 \mathrm{M}^{-1} \mathrm{~cm}^{-1}\right)$ for the $(P, P)-1$ enantiomer. Interestingly, a clear substructure is appearing and is assigned to a vibronic progression $\left(\sim 1350 \mathrm{~cm}^{-1}, \mathrm{C}=\mathrm{C}\right.$ stretching bands). A weak positive ECD band $\left(\Delta \varepsilon=+21 \mathrm{M}^{-1} \mathrm{~cm}^{-1}\right)$ is also present at $420 \mathrm{~nm}$.

CPL activity is another appealing chiroptical property of organic chiral chromophores such as helicenic derivatives and has been examined recently by us and others. ${ }^{10}$ Indeed $(M, M)$ - and $(P, P)-\mathbf{1}$ enantiomers demonstrated mirror-imaged CPL spectra (Fig. S20,

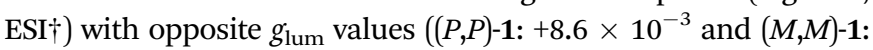
$\left.-8.4 \times 10^{-3}\right)$ around the emission maximum $(\sim 420 \mathrm{~nm})$. These values are slightly stronger than for related molecules such as

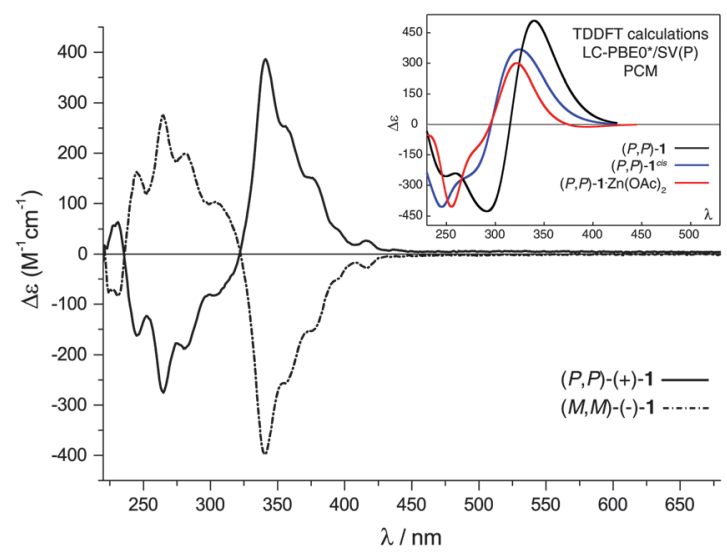

Fig. 1 Experimental ECD spectra of enantiopure $(M, M)$ - and $(P, P)-1$ and its $\mathrm{Zn}(I)$ complex $(P, P)-\mathbf{1} \cdot \mathrm{Zn}(\mathrm{OAC})_{2}\left(\mathrm{CH}_{2} \mathrm{Cl}_{2}, 2 \times 10^{-5} \mathrm{M}\right)$. Inset: Simulated spectra of $(P, P)-1$ (trans and cis) and $(P, P)-\mathbf{1} \cdot \mathrm{Zn}(\mathrm{OAC})_{2}$ (see ESI†). 
helicene-bipyridine derivatives $\left(g_{\text {lum }} \sim \pm 10^{-3}\right)^{5 d}$ or other CPLactive organic molecules. ${ }^{11}$

The terpyridine system is a good scaffold for coordination to a variety of transition-metal centers yielding complexes with a rich variety of photophysical properties that may be appealing for device applications. $^{8,12}$ Rarely have chiral substituents been integrated within the terpy scaffold and used as chiroptical switches or chiral sensors. ${ }^{13}$ In 2004, Lehn et al. described a two-state switching system based on a terpyridine-type receptor which was activated towards substrate binding upon complexation of a zinc(II) cation. ${ }^{12 a}$ This process was based on so-called "nanomechanical motions" induced by ion binding and involving shape switching between two forms presenting different physicochemical properties, namely the metal-bound and the metal-free states. Inspired by this seminal work, we explored how Zn(II) binding to 1 could induce chemical switching of the (chir)optical properties through the large conformational changes associated with the switch from W- to U-shape geometries of the terpy moiety (Fig. 2b).

In the first instance, meso-1. $\mathrm{Zn}(\mathrm{OAc})_{2}$ complex was prepared from meso-1 ligand upon treatment with 1 equiv. of $\mathrm{Zn}(\mathrm{OAc})_{2} \cdot 2 \mathrm{H}_{2} \mathrm{O}$ in $\mathrm{CH}_{2} \mathrm{Cl}_{2}$ (see Scheme 2a). This complex was obtained quantitatively $\left(K_{\mathrm{a}}=1.98 \times 10^{6} \mathrm{M}^{-1}\right)$ and was fully characterized (see ESI $\dagger$ ). Single crystals could be grown and the X-ray structure $\left(P 12_{1} / n 1\right.$ space group, Scheme 2a) shows the pentacoordinated $\mathrm{Zn}$ centre, with two OAc and the terpy ligand in a cis geometry (U shape). Note that upon coordination, the meso-1 ligand has kept its $C_{\mathrm{S}}$ symmetry but the helical angle of the aza[6]helicene parts has increased to $77.72^{\circ}$, certainly due to steric hindrance. Overall, upon coordination to the metal ion, the two aza[6]helicene moieties have fully rotated around the $\mathrm{C}-\mathrm{C}$ bonds from one side of the central pyridyl ring to the other, thus inducing the anticipated $\mathrm{W}$ - to U-shape conformational change.

In a second stage, aliquots of $\mathrm{Zn}(\mathrm{OAc})_{2} \cdot 2 \mathrm{H}_{2} \mathrm{O}$ were added to $(M, M)$ - and $(P, P)-\mathbf{1}$ and the complexation process (Fig. 2a and b) was followed by UV-vis and ECD spectroscopy ( 0.2 equivalents of $\mathrm{Zn}(\mathrm{OAc})_{2}$ were added until saturation at 1.0-1.2 equiv.). Large changes were observed in the UV-vis spectrum of $\left(P^{*}, P^{*}\right)-\mathbf{1} \neq$ upon $\mathrm{Zn}$ (II) binding, as depicted in Fig. 2c, with the presence of several isosbestic points, showing that the two species are in equilibrium. The solution turned from pale yellow to dark yellow colour. Curve fitting of the absorption variation at $432 \mathrm{~nm}$ revealed the formation of a $1: 1$ binding model with a high association constant $\left(K_{\mathrm{a}}=1.16 \times 10^{6} \mathrm{M}^{-1}\right)$. Substantial modifications were also observed for chiroptical properties of $(P, P)-\mathbf{1}$ upon $\mathrm{Zn}$ (II) binding (see Fig. 1 and 2d). For example, the strong, positive ECD-active band at $341 \mathrm{~nm}$ decreases from +388 to $+220 \mathrm{M}^{-1} \mathrm{~cm}^{-1}$, a band around $310 \mathrm{~nm}$ increases and gains significant positive intensity (from -70 to $+90 \mathrm{M}^{-1} \mathrm{~cm}^{-1}$ ), and a new positive band of low intensity appears at $430 \mathrm{~nm}\left(\Delta \varepsilon=+26 \mathrm{M}^{-1} \mathrm{~cm}^{-1}\right)$, while the molar rotation slightly increases $\left((P, P)-\mathbf{1} \cdot \mathrm{Zn}(\mathrm{OAc})_{2}:[\alpha]_{\mathrm{D}}^{23}=+2300,[\phi]_{\mathrm{D}}^{23}=\right.$ $+17300\left( \pm 5 \%, \mathrm{CH}_{2} \mathrm{Cl}_{2}, 2.18 \times 10^{-4} \mathrm{M}\right)$, vide supra). Similarly, the luminescence profile of $\mathbf{1}$ significantly changes upon adding $\mathrm{Zn}(\mathrm{OAc})_{2}$, with the appearance of a structureless intense fluorescence emission at $480 \mathrm{~nm}(\phi=19 \%, \tau=3.4 \mathrm{~ns}$, see Fig. 2e) and CPL activity at this wavelength with $g_{\text {lum }}$ values of $+1.2 \times 10^{-3}$ and $-1.4 \times 10^{-3}$ for $(P, P)-\mathbf{1} \cdot \mathrm{Zn}(\mathrm{OAc})_{2}$ and $(M, M)-\mathbf{1} \cdot \mathrm{Zn}(\mathrm{OAc})_{2}$, respectively (see ESI $\dagger$ ). The emission colour turned from blue to green.

Calculations at the LC-PBE0*/SV(P) level ${ }^{14}$ with a continuum solvent model for $\mathrm{CH}_{2} \mathrm{Cl}_{2}$ reproduce these modifications well and link them predominantly to the large conformational changes in the structure of the ligand 1 upon $\mathrm{Zn}$ (II) coordination. The simulated ECD spectrum of ligand $\mathbf{1}$ in the cis conformation of the terpy unit indeed clearly resembles the one calculated for $\mathbf{1} \cdot \mathrm{Zn}(\mathrm{OAc})_{2}$ (Fig. 1). Additionally, the $\mathrm{Zn}$ (II) complexation has a strong effect on the LUMO and LUMO+1 of 1 (both $\pi^{*}$ ), leading to a concentration of their density around the zinc ion in the terpyridine part of the ligand (see ESI $\dagger$ for the MO analysis). ${ }^{5 d}$ The HOMO and other high lying occupied $\pi$-orbitals remain helicene-centered and therefore the a)
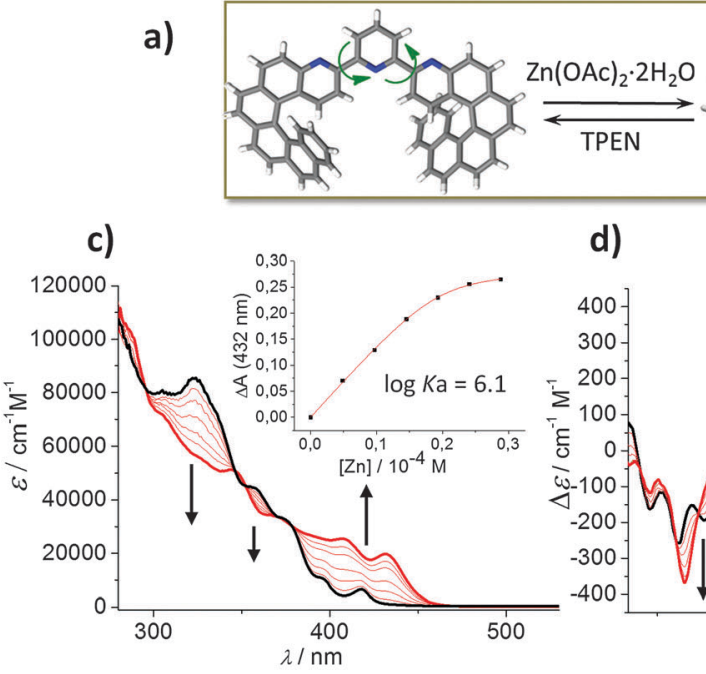

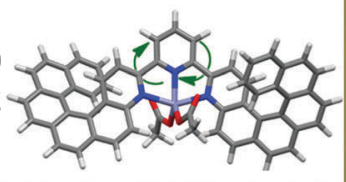

d)

b)

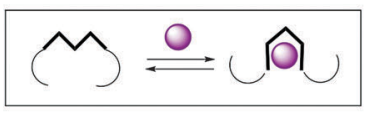

e)
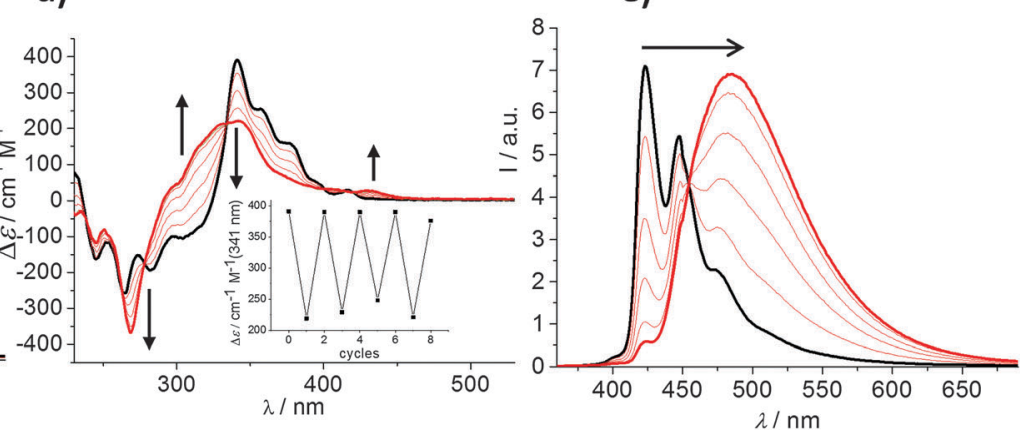

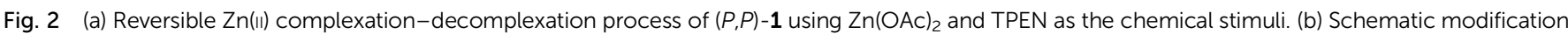

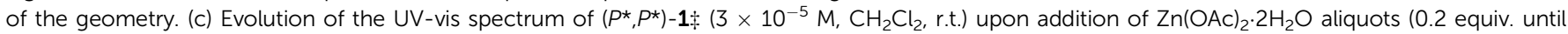

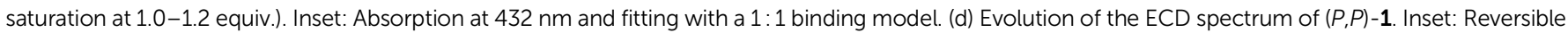
$\mathrm{ECD}_{341 \mathrm{~nm}}$ switching process. (e) Evolution of the fluorescence of $(P, P)-\mathbf{1}\left(\lambda_{\text {ex }}=350 \mathrm{~nm}, 2.2 \times 10^{-5} \mathrm{M} \mathrm{CH}_{2} \mathrm{Cl}_{2}, \mathrm{r.t}\right.$.). 
complexation strongly increases the character of charge-transfer from the helicene to the terpyridine part of the ligand in the lowenergy part of the spectrum. ${ }^{5 d}$ Note that $\mathrm{Zn}$ orbitals were not found to contribute to the $\pi$-conjugated system of the helicene ligand, as expected for closed-shell $\mathrm{d}^{10}$ metal centers. The primary effect of the $\mathrm{Zn}$ moiety is therefore to activate the structural transformation of the aza[6]helicene fragments, rigidify the system, and induce chargetransfer excitations within the ligand. The calculations also correctly reproduce changes in the $\mathrm{S}_{1}-\mathrm{S}_{0}$ (HOMO-LUMO) emission upon $\mathrm{Zn}$ (II) complexation, which is in line with the noticeable energetic stabilization of the LUMO in the complex relative to the pristine ligand: from $419 \mathrm{~nm}, g_{\text {lum }}=+6.8 \times 10^{-3}$ computed for $(P, P)-1$ to $452 \mathrm{~nm}, g_{\text {lum }}=+1.1 \times 10^{-3}$ for $(P, P)-\mathbf{1} \cdot \mathrm{Zn}(\mathrm{OAc})_{2}$ (vide supra, see $\mathrm{ESI} \dagger$ ).

In order to verify the reversibility of the $\mathrm{Zn}(\mathrm{II})$ binding process, $N, N, N^{\prime}, N^{\prime}$-tetrakis(2-pyridylmethyl)ethane-1,2-diamine (TPEN) was utilized as a competitive ligand for zinc: upon treatment with TPEN, the system returned to its original state, i.e. to the native chiral $(P, P)$ and $(M, M)$-1 ligands. Up to 9-10 steps could be performed upon successive additions of 1 equiv. of $\mathrm{Zn}(\mathrm{OAc})_{2}$ and TPEN, following the ECD tuning at a selected wavelength where the changes are very high (for example $\Delta \Delta \varepsilon=175 \mathrm{M}^{-1} \mathrm{~cm}^{-1}$ at $341 \mathrm{~nm}$, see inset of Fig. $2 \mathrm{~d}$ ). Overall, this system is behaving as a chiroptical switch offering multioutput read-out (UV-vis, ECD, luminescence and CPL). Furthermore, the switching process triggers conformational changes and molecular motion around the $\mathrm{Zn}$ centre, from a clear trans (W-shape) conformation in the free ligand to a cis (U-shape) one in the Zn-complex. To our knowledge, this constitutes a new type of helicene-based chiroptical switching. ${ }^{4}$ In conclusion, the preparation of unprecedented bis-helicenic terpy ligand has opened new perspectives in multifunctional chiral complexes and chiroptical switches; coordination to other metallic ions is under current investigation.

We thank the Ministère de l'Education Nationale, de la Recherche et de la Technologie, the Centre National de la Recherche Scientifique (CNRS), the ANR (12-BS07-0004-METALHEL-01), the Région Bretagne (SAD CHIROPEM) and the LIA Rennes-Durham for financial support. M. S.-H. is grateful for financial support from the Ministry of Science and Higher Education in Poland ('Outstanding Young Scientist' scholarship). J. A. acknowledges the National Science Foundation (CHE 1265833) for financial support and the Center for Computational Research (CCR) at the University at Buffalo for computational resources. G. M. thanks the NIH, Minority Biomedical Research Support (grant 1 SC3 GM089589-07) and the Henry Dreyfus Teacher-Scholar Award for financial support.

\section{Notes and references}

$\ddagger\left(P^{*}, P^{*}\right)$-1 means the racemic mixture of $(P, P)$ - and $(M, M)-\mathbf{1}$.

1 (a) J. W. Canary, S. Mortezaei and J. Liang, Coord. Chem. Rev., 2010, 254, 2249; (b) J. W. Canary and Z. Dai, Dynamic stereochemistry and chiroptical spectroscopy of metallo-organic compounds, in Comprehensive Chiroptical Spectroscopy, ed. N. Berova, R. W. Woody, P. Polavarapu and K. Nakanishi, John Wiley \& Sons, Hoboken, NJ, USA, 2012, vol. 2; (c) H. Miyake and H. Tsukube, Chem. Soc. Rev., 2012, 41, 6977; (d) Z. Dai, J. Lee and W. Zhang, Molecules, 2012, 17, 1247; (e) J. Crassous, Chem. Commun., 2012, 48, 9684.

2 (a) B. L. Feringa and W. R. Browne, Molecular Switches, Wiley-VCH, 2nd edn, 2011; (b) V. Balzani, A. Credi and M. Venturi, Molecular Devices and Machines, Concepts and Perspectives for the Nanoworld, Wiley-VCH, Weinheim, 2008.
3 Selected recent reviews: (a) Y. Shen and C.-F. Chen, Chem. Rev., 2012, 112, 1463; (b) M. Gingras, Chem. Soc. Rev., 2013, 42, 1051; (c) N. Saleh, C. Shen and J. Crassous, Chem. Sci., 2014, 5, 3680; (d) J. Bosson, J. Gouin and J. Lacour, Chem. Soc. Rev., 2014, 43, 2824.

4 For a review see: H. Isla and J. Crassous, C. R. Chim., 2016, 19, 39 and references therein.

5 (a) E. Anger, M. Srebro, N. Vanthuyne, L. Toupet, S. Rigaut, C. Roussel, J. Autschbach, J. Crassous and R. Réau, J. Am. Chem. Soc., 2012, 134, 15628; (b) E. Anger, M. Srebro, N. Vanthuyne, C. Roussel, L. Toupet, J. Autschbach, R. Réau and J. Crassous, Chem. Commun., 2014, 50, 2854; (c) M. Srebro, E. Anger, B. Moore, II, N. Vanthuyne, C. Roussel, R. Réau, J. Autschbach and J. Crassous, Chem. - Eur. J., 2015, 21, 17100; (d) N. Saleh, B. Moore, II, M. Srebro, N. Vanthuyne, L. Toupet, J. A. G. Williams, C. Roussel, K. K. Deol, G. Muller, J. Autschbach and J. Crassous, Chem. - Eur. J., 2015, 21, 1673.

6 Selected: (a) T. R. Kelly, H. De Silva and R. A. Silva, Nature, 1999, 401, 150; (b) N. Koumura, R. W. J. Zijlstra, R. A. van Delden, N. Harada and B. L. Feringa, Nature, 1999, 401, 152; (c) J. V. Hernandez, E. R. Kay and D. A. Leigh, Science, 2004, 306, 1532; (d) R. A. van Delden, M. K. J. ter Wiel, M. M. Pollard, J. Vicario, N. Koumura and B. L. Feringa, Nature, 2005, 437, 1337; (e) K. Miwa, Y. Furusho and E. Yashima, Nat. Chem., 2010, 2, 444; $(f)$ H. L. Tierney, C. J. Murphy, A. D. Jewell, A. E. Baber, E. V. Iski, H. Y. Khodaverdian, A. F. McGuire, N. Klebanov and E. C. H. Sykes, Nat. Nanotechnol., 2011, 6, 625; $(g)$ U. G. E. Perera, F. Ample, H. Kersell, Y. Zhang, G. Vives, J. Echeverria, M. Grisolia, G. Rapenne, C. Joachim and S.-W. Hla, Nat. Nanotechnol., 2013, 8, 46; (h) G. Haberhauer, Angew. Chem., Int. Ed., 2008, 47, 3635; (i) Y. Suzuki, T. Nakamura, H. Iida, N. Ousaka and E. Yashima, J. Am. Chem. Soc., 2016, DOI: 10.1021/jacs.6b00787.

7 (a) Y. D. M. Champouret, R. K. Chaggar, I. Dadhiwala, J. Fawcett and G. A. Solan, Tetrahedron, 2006, 62, 79; (b) D. A. Lightner, D. T. Hefelfinger, T. W. Powers, G. W. Frank and K. N. Trueblood, J. Am. Chem. Soc., 1972, 94, 3492.

8 A. Wild, A. Winter, F. Schlüttera and U. S. Schubert, Chem. Soc. Rev., 2011, 40, 1459.

9 D. Mendola, N. Saleh, N. Vanthuyne, C. Roussel, L. Toupet, F. Castiglione, T. Caronna, A. Mele and J. Crassous, Angew. Chem., Int. Ed., 2014, 53, 5786.

10 Selected examples of CPL active helicenes: (a) J. E. Field, G. Muller, J. P. Riehl and D. Venkataraman, J. Am. Chem. Soc., 2003, 125, 11808; (b) Y. Sawada, S. Furumi, A. Takai, M. Takeuchi, K. Noguchi and K. Tanaka, J. Am. Chem. Soc., 2012, 134, 4080; (c) K. E. S. Phillips, T. J. Katz, S. Jockusch, A. J. Lovinger and N. J. Turro, J. Am. Chem. Soc., 2001, 123, 11899; (d) T. Kaseyama, S. Furumi, X. Zhang, K. Tanaka and M. Takeuchi, Angew. Chem., Int. Ed., 2011, 50, 3684; (e) C. Shen, E. Anger, M. Srebro, N. Vanthuyne, K. K. Deol, T. D. Jefferson Jr., G. Muller, J. A. G. Williams, L. Toupet, C. Roussel, J. Autschbach, R. Réau and J. Crassous, Chem. Sci., 2014, 5, 1915; $(f)$ K. Nakamura, S. Furumi, M. Takeuchi, T. Shibuya and K. Tanaka, J. Am. Chem. Soc., 2014, 136, 5555; $(g)$ N. Saleh, M. Srebro, T. Reynaldo, N. Vanthuyne, L. Toupet, V. Y. Chang, G. Muller, J. A. G. Williams, C. Roussel, J. Autschbach and J. Crassous, Chem. Commun., 2015, 51, 3754; (h) Y. Yamamoto, H. Sakai, J. Yuasa, Y. Araki, T. Wada, T. Sakanoue, T. Takenobu, T. Kawai and T. Hasobe, Chem. - Eur. J., 2016, 22, 4263.

11 See reviews: (a) H. Maeda and Y. Bando, Pure Appl. Chem., 2013, 85, 1967; (b) E. M. Sanchez-Carnerero, A. R. Agarrabeitia, F. Moreno, B. L. Maroto, G. Muller, M. J. Ortiz and S. de la Moya, Chem. - Eur. J., 2015, 21, 13488; (c) J. Kumar, T. Nakashima and T. Kawai, J. Phys. Chem. Lett., 2015, 6, 3445-3452.

12 (a) A. Petitjean, R. G. Khoury, N. Kyritsakas and J.-M. Lehn, J. Am. Chem. Soc., 2004, 126, 6637; (b) B. Doistau, A. Tron, S. A. Denisov, G. Jonusauskas, N. D. McClenaghan, G. Gontard, V. Marvaud, B. Hasenknopf and G. Vives, Chem. - Eur. J., 2014, 20, 15799; (c) B. Doistau, J.-L. Cantin, L.-M. Chamoreau, V. Marvaud, B. Hasenknopf and G. Vives, Chem. Commun., 2015, 51, 12916; (d) A. Fermi, G. Bergamini, M. Roy, M. Gingras and P. Ceroni, J. Am. Chem. Soc., 2014, 136, 6395.

13 (a) M. Ziegler, V. Monney, H. Stoeckli-Evans, A. Von Zelewsky, I. Sasaki, G. Dupic, J.-C. Daran and G. G. A. Balavoine, J. Chem. Soc., Dalton Trans., 1999, 667; (b) S. Bernhard, K. Takada, D. J. Díaz, H. D. Abruña and H. Mürner, J. Am. Chem. Soc., 2001, 123, 10265; (c) S. Bernhard, J. I. Goldsmith, K. takada and H. D. Abruña, Inorg. Chem., 2003, 42, 4389; (d) A. Khatyr and R. Ziessel, Org. Lett., 2001, 3, 1857; (e) S. Bezer, S. Rapireddy, Y. A. Skorik, D. H. Ly and C. Achim, Inorg. Chem., 2011, 50, 11929.

14 (a) J. Autschbach, Chirality, 2009, 21, E116; (b) J. Autschbach, L. NitschVelasquez and M. Rudolph, Top. Curr. Chem., 2011, 298, 1; (c) J. Autschbach and M. Srebro, Acc. Chem. Res., 2014, 47, 2592; (d) B. Pritchard and J. Autschbach, ChemPhysChem, 2010, 11, 2409. 